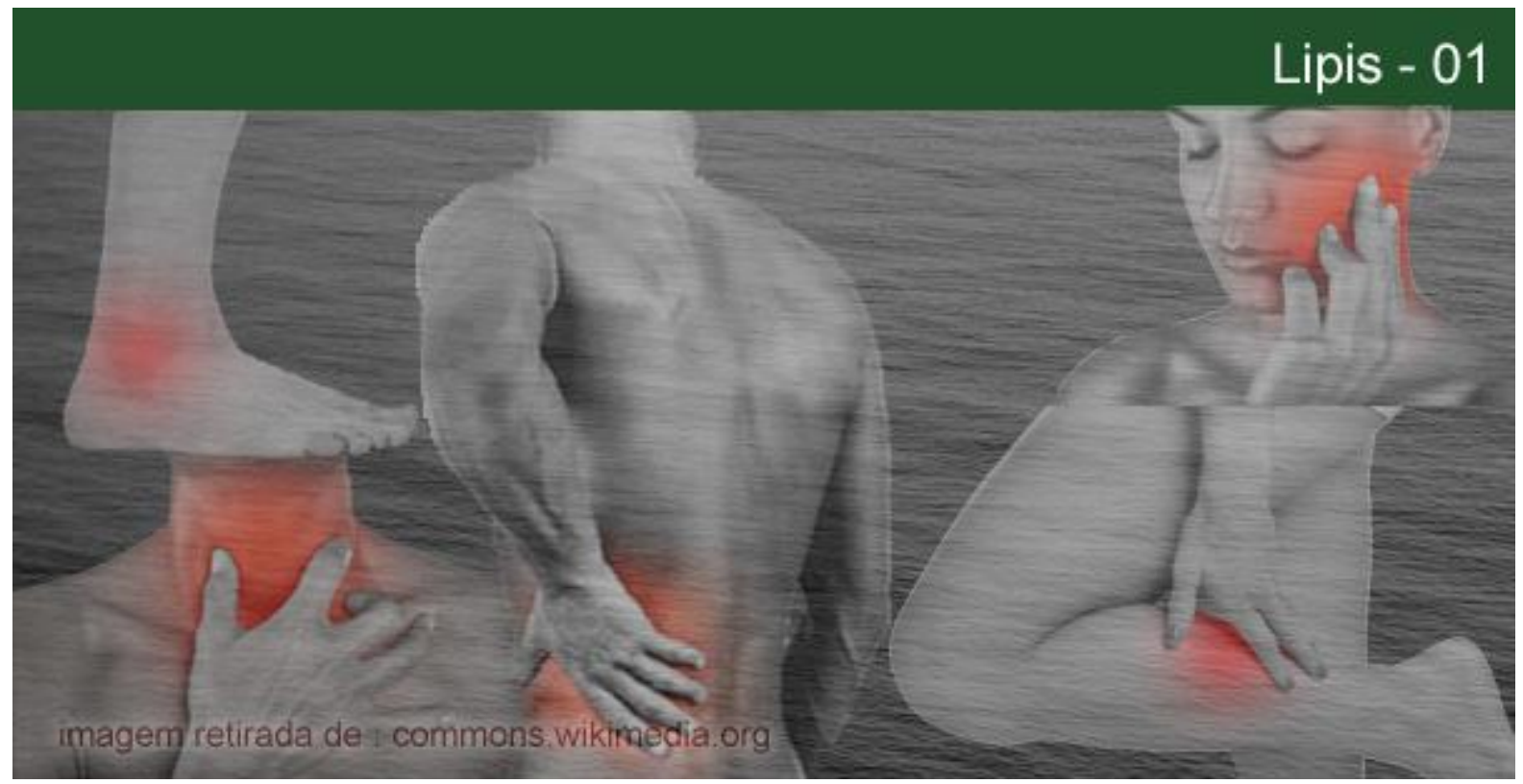

\title{
A FIBROMIALGIA SOB A ÓTICA PSICANALÍTICA: UM BREVE PANORAMA
}

Elisa Pellosi de Freitas

Psicóloga pela Universidade Federal de Uberlândia (UFU).E-mail: elisapellosi@hotmail.com.

\section{Rodrigo Sanches Peres}

Psicólogo pela Universidade Estadual Paulista (Unesp). Especialista em Psicologia Clínica pelo Conselho Federal de Psicologia (CFP). Mestre e Doutor em Psicologia pela Universidade de São Paulo (USP), com Pósdoutorado pela Universidade de Lisboa (UL). Membro do Grupo de Trabalho "Psicanálise e Clínica Ampliada" da Associação Nacional de Pesquisa e Pós-Graduação em Psicologia (ANPEPP). Professor do Programa de Pós-Graduação em Psicologia da Universidade Federal de Uberlândia (UFU). E-mail: rodrigosanchesperes@yahoo.com.br.

Resumo: Recentemente, algumas pesquisas vêm se apoiando no arcabouço teórico da Psicanálise com o intuito de lançar luzes sobre os aspectos subjetivos da fibromialgia. O presente estudo teve como propósito, por meio do empreendimento de uma revisão da literatura, estabelecer um breve panorama das publicações científicas difundidas em diferentes veículos latino-americanos e que abordam a fibromialgia sob a ótica psicanalítica. Para tanto, foram realizadas buscas nas bases de dados SciELO-Brasil, LILACS, PEPsic e Psique. As publicações localizadas foram selecionadas mediante critérios referentes ao enfoque e ao tipo. Todas as publicações selecionadas foram recuperadas na íntegra e avaliadas em função de um conjunto de dimensões. Foram localizadas 505 publicações, no total. Excluindo-se as repetições, restaram 376 publicações. Destas, contudo, apenas 13 constituíram o corpus do presente estudo, sendo que o número elevado de descartes já era esperado devido à abrangência da estratégia de busca utilizada. Constatou-se que predominaram publicações derivadas de estudos teórico-clínicos e foi observada certa diversificação quanto aos autores de referência. Os resultados das publicações não são conclusivos quanto às possibilidades de a fibromialgia constituir uma variante da histeria moldada pelos processos de subjetivação contemporâneos ou de possuir um caráter transnosográfico. Porém, foi recorrente a associação entre a síndrome e vivências traumáticas precoces, sobretudo relacionadas à sexualidade. O presente estudo, assim, possibilita um mapeamento do conhecimento já produzido sobre a fibromialgia sob a ótica da Psicanálise e aponta caminhos para a realização de novas pesquisas, as quais, inclusive, se revelam necessárias face à escassez de publicações disponíveis atualmente.

Palavras-chave: Fibromialgia. Psicanálise. Subjetividade.

\section{POLÊM!CA $\mid$ LABORE}

Polêmica - Revista Eletrônica da Uerj - Rua São Francisco Xavier, 524, $1^{\circ}$ andar

bloco D, sl.1001 • Tels.: +55 21 2334-4088/4087 • http://www.e-publicacoes.uerj.br/index.php/polemica/index http://www.labore.uerj.br • laboreuerj@yahoo.com.br 


\title{
FIBROMYALGIA FROM PSYCHOANALYTIC PERSPECTIVE: \\ A BRIEF OVERVIEW
}

\begin{abstract}
Recently, some researches have been using the theoretical framework of Psychoanalysis in order to shed light on the subjective aspects of fibromyalgia. The purpose in this study, through the development of a literature review, was to establish a brief overview of scientific publications disseminated in various Latin American vehicles and that address fibromyalgia from psychoanalytic perspective. Therefore, electronic searches were developed in the databases SciELO-Brazil, LILACS, PEPsic, and Psique. The publications located were selected using criteria related to the focus and the tipo. All selected publications were fully retried and assessed in function of a set of dimensions. Were located 505 publications in total. Excluding the repetitions, 376 publications remained. Of these, however, only 13 constituted the corpus of this study. The large number of eliminations was expected due to the range of the search strategy used. It was verified that publications deriving from theoretical-clinical studies were predominant and that diversified authors were referred to. The results of the publications are not conclusive with regard to the possibility that fibromyalgia is a variant of the hysteria molded by the contemporary subjectivation processes or has a transnosographic background. However, was recurrent the association between the syndrome and the early traumatic experiences, mainly related to sexuality. Thus, this study permits mapping the knowledge produced on fibromyalgia in the light of Psychoanalysis and appoints possibilities for further research, which show to be necessary in view of the lack of publications currently available.
\end{abstract}

Keywords: Fibromyalgia. Psychoanalysis. Subjectivity.

\section{Introdução}

A fibromialgia é uma síndrome reumatológica, predominantemente feminina, que se caracteriza pela ocorrência de dores musculoesqueléticas difusas, crônicas, desvinculadas de alterações orgânicas passíveis de detecção e invariavelmente relacionadas a alterações no humor, na memória e no sono (CLAUW, 2014; BELLATO et al., 2012). Há, portanto, uma série de dificuldades quanto à objetivação de seu quadro clínico. Apesar disso, o predomínio de uma perspectiva positivista tem levado muitos pesquisadores - inclusive no campo da Psicologia - a negligenciarem os aspectos subjetivos da fibromialgia, o que, em nosso entendimento, configura um contrassenso. E tal entendimento encontra respaldo no fato de a dor, sintoma central da síndrome, ser enquadrada como um fenômeno essencialmente subjetivo, concernente a "uma experiência sensorial e emocional desagradável associada a uma lesão real ou potencial dos tecidos, ou descrita em termos de tal dano" (tradução nossa) (TASK FORCE ON TAXONOMY OF THE INTERNATIONAL ASSOCIATION FOR THE STUDY OF PAIN, 1994, p. 210).

Recentemente, algumas pesquisas, com desenhos metodológicos heterogêneos, vêm se apoiando no arcabouço teórico da Psicanálise - definida por seu criador como a "ciência dos processos mentais inconscientes" (FREUD, 1996b, p. 254) - com o intuito de lançar luzes sobre os aspectos subjetivos da fibromialgia. Um mapeamento do conhecimento produzido pelas referidas pesquisas se justifica considerando-se que pode funcionar como ponto de

\section{POLÊM!CA $\mid$ LABORE}

Polêmica - Revista Eletrônica da Uerj - Rua São Francisco Xavier, 524, $1^{\circ}$ andar

bloco D, sl.1001 • Tels.: +55 21 2334-4088/4087 • http://www.e-publicacoes.uerj.br/index.php/polemica/index

http://www.labore.uerj.br • laboreuerj@yahoo.com.br 
partida para o desenvolvimento de novos estudos, bem como é capaz de proporcionar informações úteis para a prática clínica de diferentes profissionais de saúde. Afinal, até mesmo em conformidade com as diretrizes estabelecidas por entidades médicas como a Académie Nationale de Médecine (MENKÈS, GODEAU, 2007) e a Sociedade Brasileira de Reumatologia (HEYMANN et al., 2010), dentre outras, o tratamento da fibromialgia deve ser planejado face às especificidades de cada caso e implementado a partir de uma abordagem multidisciplinar.

Dessa forma, o presente estudo teve como propósito, por meio do empreendimento de uma revisão da literatura, estabelecer um breve panorama das publicações científicas difundidas em diferentes veículos latino-americanos e que abordam a fibromialgia sob a ótica psicanalítica. Mais especificamente, buscamos responder à seguinte questão norteadora: Quais são as principais tendências apresentadas pelas publicações em pauta em termos: (1) de seus objetivos, (2) de seu formato, (3) de seus autores de referência, e (4) de seus resultados?. E consideramos relevante explicitar que o presente estudo pode ser enquadrado como uma revisão integrativa, modalidade de revisão da literatura em que se admite a inclusão, no corpus de análise, de pesquisas realizadas a partir da utilização de desenhos metodológicos diversificados e publicadas em veículos variados (SOARES et al., 2014). Nesse sentido, as revisões integrativas são consideradas mais inclusivas e tratam de tópicos mais amplos do que as revisões sistemáticas, que comumente privilegiam pesquisas empíricas e se debruçam sobre questões mais circunscritas (SOUZA, SILVA, CARVALHO, 2010).

\section{Método}

Tendo em vista o objetivo do presente estudo, optamos pela realização on-line de buscas eletrônicas nas bases de dados SciELO-Brasil, LILACS, PEPsic e Psique. A SciELOBrasil se afigura como um portal de periódicos brasileiros e possui caráter multidisciplinar, ao passo que a LILACS contempla a produção científica - em um sentido mais amplo - relativa ao campo da saúde e oriunda da América Latina e Caribe. Já a PEPsic é especializada em Psicologia e abrange periódicos de toda a América Latina. Por fim, a Psique se diferencia das demais por ser constituída exclusivamente pelo acervo - nacional e internacional - da Sociedade Brasileira de Psicanálise de São Paulo. Ressalte-se que, a despeito de o emprego da

\section{POLÊM!CA $\mid$ LABORE}


Psique em revisões da literatura não ser recorrente, tal base de dados foi considerada relevante face às especificidades do presente estudo.

As buscas foram concluídas no dia 11 de janeiro de 2016, a partir da inserção do descritor "fibromialgia" nos campos "resumo", na SciELO-Brasil e na PEPsic, ou "palavras do resumo", na LILACS. Já a Psique oferecia apenas a possibilidade de busca com formulário básico, sem escolha do campo. Vale destacar também que, para viabilizar um levantamento bibliográfico completo, optamos por um procedimento de busca simples, pois consultas preliminares revelaram que o cruzamento de descritores seria demasiadamente restritivo. Pela mesma razão, foi preterida a utilização de quaisquer limites ou filtros - em relação à data de publicação ou idioma, por exemplo - oferecidos pelas bases de dados.

Após a realização das buscas, o título de todas as publicações obtidas foi inicialmente examinado para subsidiar a eliminação de eventuais duplicidades. A seguir, os resumos - ou, em certos casos, os textos completos, como será detalhado adiante - das publicações selecionadas mediante o emprego desse procedimento inicial foram submetidos a uma leitura preliminar, cujo propósito básico foi determinar o material que, efetivamente, constituiria o corpus do presente estudo. Realizamos tal leitura de modo independente e com base em dois critérios de inclusão. O primeiro foi referente ao enfoque e o segundo ao tipo. Dessa maneira, definiu-se que seriam selecionadas somente as publicações: (1) que de fato abordassem a fibromialgia sob a ótica psicanalítica e (2) veiculadas como artigos em periódicos científicos ou trabalhos completos em anais de eventos ou capítulos de livros ou livros ou dissertações ou teses de origem latino-americana.

Todas as publicações que integraram o corpus do presente estudo foram recuperadas na íntegra e submetidas à avaliação mediante a execução da leitura exaustiva de cada uma delas, também de modo independente. Para subsidiar a devida organização, os achados decorrentes dessa leitura exaustiva foram estruturados em quatro dimensões de análise estabelecidas em consonância com a questão norteadora, a saber: (1) objetivo principal; (2) formato; (3) autores de referência; e (4) resultados principais. Acrescentamos que as três primeiras constituíram dimensões de análise básicas. Já a quarta dimensão foi enquadrada como uma dimensão de análise avançada, à qual foi concedido maior aprofundamento. E vale destacar que os achados inicialmente consensuais foram aceitos automaticamente. Já os

\section{POLÊM!CA $\mid$ LABORE}


achados inicialmente discordantes foram discutidos caso a caso até que se chegasse a um comum acordo.

\section{Resultados e discussão}

As buscas nas bases de dados subsidiaram a localização de 505 publicações, no total, sendo 353 na LILACS, 125 na SciELO-Brasil, 17 na Psique e 10 na PEPsic. Porém, com o descarte das duplicidades, restaram 376 publicações. A leitura dos resumos levou ao descarte de 353 destas publicações, as quais, em nossa avaliação, não preenchiam os critérios de inclusão. Por fim, outras 10 publicações somente puderam ser descartadas com segurança a partir da leitura dos textos completos, pois os resumos não foram considerados suficientemente informativos. Ressalte-se que a grande maioria das publicações descartadas contemplava apenas aspectos biomédicos da fibromialgia, de forma que não atendia ao primeiro critério de inclusão. E o número elevado de descartes já era esperado, considerandose a abrangência da estratégia de busca utilizada.

Portanto, das 505 publicações localizadas, apenas 13 constituíram o corpus do presente estudo, a saber: Besset (2014), Bittencourt e Pollo (2014), Britto, Santos e Lucia (2014), Santos e Rudge (2014), Filippon et al. (2013), Filippon (2012), Semer (2012), Silva e Rumim (2012), Aragon (2010), Besset et al. (2010), Lima e Carvalho (2008), Slompo e Bernardino (2006) e Leite e Pereira (2003). É interessante sublinhar que todas as publicações selecionadas são brasileiras e, salvo aquela de autoria de Filippon (2012), se enquadram como artigos veiculados em periódicos científicos, apesar de, como já mencionado, terem sido consultadas bases de dados que contemplam a América Latina e o Caribe e não se limitam a periódicos, posto que também englobam teses, dissertações e livros, por exemplo.

A partir da avaliação da primeira dimensão de análise, constamos que em três publicações - Britto, Santos e Lucia (2014), Santos e Rudge (2014) e Filippon et al. (2013) o objetivo principal foi compreender a dor crônica como expressão de um trauma nãoelaborado. Além disso, Semer (2012), Silva e Rumim (2012) e Lima e Carvalho (2008) elegeram como foco o relato de experiências situadas no campo da clínica psicanalítica voltadas ao tratamento de pacientes com fibromialgia, ao passo que Bittencourt e Pollo (2014) e Slompo e Bernardino (2006) estabeleceram aproximações entre a fibromialgia e a histeria. As demais publicações apresentaram objetivos mais diversificados. Considerando-se a

\section{POLÊM!CA $\mid$ LABORE}


escassez de estudos que abordam a fibromialgia sob a ótica psicanalítica, obviamente o assunto não se encontra esgotado. Ainda assim, seria interessante se novas pesquisas buscassem se diferenciar daquelas já publicadas em termos de seus objetivos, de forma a contemplar questões que não foram exploradas até aqui, dentre as quais podemos destacar, por exemplo, a identificação de eventuais convergências e divergências no que se refere à estrutura e à dinâmica psíquicas de homens e mulheres com fibromialgia.

Quanto à segunda dimensão de análise, inicialmente é preciso esclarecer que elaboramos uma categorização em função da qual as publicações foram enquadradas em quatro formatos: (1) teórico, por adotar como foco principal a discussão de conceitos e constructos a partir de uma perspectiva reflexiva e crítica; (2) teórico-clínico, por articular a discussão de conceitos e constuctos à análise de material oriundo de experiências situadas no campo da clínica psicanalítica; (3) empírico, por envolver dados coletados em campo especialmente para fins de pesquisa; e (4) estudo de caso, por priorizar a análise em profundidade de um caso (quer seja um único sujeito ou um grupo de sujeitos que possa ser tomado como uma unidade) em particular.

Os achados relativos à segunda dimensão de análise revelam que mais da metade das publicações - Besset (2014), Bittencourt e Pollo (2014), Semer (2012), Silva e Rumim (2012), Besset et al. (2010), Slompo e Bernardino (2006) e Leite e Pereira (2003) - deriva de estudos teórico-clínicos. Em certo sentido, tal achado já era esperado, na medida em que, conforme Elia (2000), a pesquisa em Psicanálise tipicamente parte da clínica e a ela retorna. Por outro lado, atualmente há, no campo psicanalítico, além do notório pluralismo na teoria, o pluralismo na pesquisa (DREHER, 2008). Logo, seria mais condizente com esta situação a opção, em pesquisas futuras, por desenhos metodológicos menos frequentes até o momento, obviamente desde que em consonância com os objetivos estabelecidos para as mesmas, o que resultaria em publicações mais variadas no tocante ao formato. Pesquisas empíricas no âmbito da clínica psicanalítica, por exemplo, podem auxiliar na avaliação de processos e resultados junto a pacientes com fibromialgia, e eventualmente revelar se existem ou não peculiaridades a esse respeito em se tratando de tal público ${ }^{1}$.

\footnotetext{
${ }^{1}$ Um detalhamento sobre os desafios e as possibilidades no tocante às pesquisas empíricas em Psicanálise foge ao escopo do presente estudo, mas foi estabelecido por Campezatto, Nunes e Silva (2014) em um texto ao qual remetemos o leitor.
}

\section{POLÊM!CA $\mid$ LABORE}


Acerca da terceira dimensão de análise, notamos que houve certa diversificação quanto aos autores de referência das publicações selecionadas, principalmente no que tange aos contemporâneos, que variaram de Luís Chiozza (Argentina) e Pierre Fédida (França) a Joel Birman (Brasil), para citar apenas alguns. Este resultado reflete o pluralismo na teoria que, como já mencionado, se apresenta como uma marca distintiva do campo psicanalítico na atualidade. E, para Eizirik (2005), a característica em questão pode ser entendida como um sinal de vitalidade decorrente do fato de a Psicanálise constituir uma obra em construção e atravessar um momento de transição, no qual certos pressupostos teóricos são revisados a partir de novos desenvolvimentos teóricos e se busca o estabelecimento de diálogos com outros saberes. Mas é preciso esclarecer que tal entendimento não é consensual, pois o autor citado assume uma posição intermediária no contexto dos debates internos sobre o common ground psicanalítico.

No que diz respeito à quarta e última dimensão de análise, cumpre assinalar que as três publicações voltadas ao estabelecimento de relações entre o surgimento da fibromialgia e a vivência de traumas chegaram a constatações que, em linhas gerais, podem ser consideradas compatíveis. Ocorre que Britto et al. (2014) propuseram que, no âmbito do caso do qual se ocuparam, um trauma não-elaborado na infância - causado por abuso sexual, especificamente - levou à repetição de situações dolorosas em uma tentativa inconsciente de elaboração, fazendo com que a paciente se colocasse tanto no papel de "abusada" quanto no papel de "abusadora" ao se comportar de forma hostil consigo mesma e com seu próprio corpo, o que teria favorecido a eclosão da síndrome e outras complicações de saúde na idade adulta.

Já Santos e Rudge (2014) apontaram que a dor física, em especial a dor crônica, sendo concebida como uma forma de expressão de um trauma não-elaborado, poderia ser aproximada da compulsão à repetição e, assim, se assemelharia mais a uma inibição do que a um sintoma. Além disso, as autoras defenderam que a dor estaria ligada a níveis elevados de investimento libidinal em relação ao corpo ou a um objeto perdido, de maneira semelhante ao que ocorre na hipocondria e na melancolia, respectivamente. E Filippon et al. (2013) notaram associação entre história de trauma na infância e perda de funcionalidade em mulheres adultas com fibromialgia, nomeadamente em pacientes sem depressão. Tal achado foi entendido como o desdobramento de um possível recurso a uma tentativa de solução somática do trauma, a qual se afiguraria como uma espécie de acting-out no corpo.

\section{POLÊM!CA $\mid$ LABORE}


Ressalte-se que os dados reportados por Filippon et al. (2013) são derivados da dissertação de mestrado da primeira autora e foram explorados a partir de formulações psicanalíticas sobre as manifestações psicossomáticas em outra publicação, que também fez parte do corpus do presente estudo. Nesta outra publicação, Filippon (2012) sustentou que a perda de funcionalidade é mais acentuada em mulheres adultas com fibromialgia e sem depressão porque as mesmas manifestariam no plano somático o impacto de traumas infantis que mulheres com fibromialgia e com depressão, revelando uma capacidade de elaboração psíquica mais desenvolvida, manifestariam no plano mental. Mas a autora sugere que as mulheres com fibromialgia e sem depressão talvez apresentassem uma condição psicopatológica designada como depressão essencial, em que as expressões sintomáticas se orientam predominantemente para a esfera física.

Malgrado o fato, já sublinhado, de as três publicações voltadas ao estabelecimento de relações entre a fibromialgia e eventos traumáticos reportarem resultados consistentes entre si, julgamos oportuno mencionar que autores como André (2015) e Mondrzak et al. (2005), dentre outros, relativizam o destaque atualmente conferido à noção de trauma no campo psicanalítico. E o fazem, mais especificamente, ao afirmar que tal noção é utilizada muitas vezes em prol de tentativas simplistas de encontrar na realidade objetiva e em acontecimentos factuais as causas do sofrimento de um sujeito. A lógica freudiana, em contraste, preconiza que o valor traumático de um evento é determinado, a rigor, pela realidade psíquica, visto que decorre da incapacidade de o indivíduo integrar efetivamente ao plano da consciência tal evento, por ser ele totalmente inesperado e/ou demasiadamente violento.

As três publicações dedicadas ao relato de experiências situadas no campo da clínica psicanalítica voltadas ao tratamento de pacientes com fibromialgia reportaram resultados que também podem ser considerados equivalentes. Afinal, para Semer (2012), o atendimento psicanalítico individual permitiu que as pacientes em pauta ampliassem seus recursos psíquicos, desenvolvessem suas capacidades de tolerância às frustrações, autocontinência simbólica e expressividade emocional, sendo que, assim, as dores gradativamente deixaram de ocupar o eixo de sustentação da identidade. Portanto, a dor, seja física ou psíquica, poderia ser compreendida como um fenômeno associado a conflitos emocionais que não foram elaborados originalmente, mas encontraram significação na situação terapêutica.

\section{POLÊM!CA $\mid$ LABORE}


Lima e Carvalho (2008), de modo semelhante, observaram que a psicoterapia breve de orientação psicanalítica auxiliou no controle dos sintomas de uma paciente ao promover o desenvolvimento de certos recursos egóicos em um processo que a levou a abandonar uma acentuada tendência à passividade e à dependência, bem como a uma melhor discriminação tanto de seus estados afetivos quanto das necessidades alheias. E Silva e Rumim (2012) afirmaram que o atendimento psicanalítico grupal possibilitou às pacientes elaborar vivências conflituosas decorrentes do afastamento do trabalho mediante a ressignificação de afetos anteriormente cindidos e a compreensão do adoecimento como forma de expressão de angústias que não haviam sido simbolizadas.

Tendo em vista o que precede, constatamos que os resultados das três publicações dedicadas ao relato de experiências situadas no campo da clínica psicanalítica voltadas ao tratamento de pacientes com fibromialgia encontram respaldo nas observações estabelecidas por Cardoso e Paraboni (2010) em uma publicação que, por não abordar especificamente da fibromialgia, não foi recuperada por meio da estratégia de localização empregada para os fins do presente estudo, mas pode ser considerada pertinente a esta oportunidade. Ocorre que, de acordo com as autoras, pacientes com dor crônica, ao apresentarem insistentemente uma queixa, ainda que relativa à dimensão física, se dirigem a alguém, o que já sinalizaria uma tentativa de entrar em contato com questões que, em um momento anterior, se revelaram refratárias à representação, mas não necessariamente seriam irrepresentáveis.

As duas publicações que se ocuparam da demarcação de pontos de convergência entre a fibromialgia e a histeria foram concordantes em seus aspectos principais. Isso porque Bittencourt e Pollo (2014) asseveraram que em ambas as condições clínicas os sintomas poderiam ser gerados por conflitos psíquicos associados a impulsos recalcados que somente encontrariam satisfação a partir da emergência de zonas erógenas e da compulsão à repetição, além de que o acesso ao gozo seria substituído pela manutenção do lugar de objeto no discurso do Outro. E, para Slompo e Bernardino (2006), haveria equivalências entre a etiologia (sensibilidade acentuada a estímulos dolorosos e história de vida marcada por traumas psíquicos) e a sintomatologia (dores difusas pelo corpo sem substrato orgânico, fadigabilidade, parestesias, ansiedade, depressão, insônia e cefaleia) da histeria e da fibromialgia. As autoras, inclusive, propuseram que a fibromialgia poderia ser compreendida como um sintoma histérico da contemporaneidade.

\section{POLÊM!CA $\mid$ LABORE}


Contudo, tanto Besset et al. (2010) quanto Leite e Pereira (2003) defenderam um outro posicionamento. De acordo com a primeira dessas publicações, na neurose, a fibromialgia poderia se equiparar a uma função de apelo decorrente de uma marcante necessidade de proteção ou a uma função de resposta a um trauma, ao passo que, na psicose, a fibromialgia corresponderia a uma função de apreensão dos limites corporais. Ou seja, a dor seria passível de diferentes tipos de uso, dependendo da estrutura psíquica do sujeito. A segunda dessas publicações sustentou que a fibromialgia poderia ser concebida como um fenômeno passível de inscrição em personalidades de organização histérica ou psicossomática. A dor física estaria associada a um hiper-investimento narcisista decorrente do abandono do investimento libidinal, além de que representaria uma possibilidade de manutenção da unidade corporal. Por outro lado, poderia servir como coordenada inicial para a manifestação de um sofrimento "perdido", que demandaria mediação psíquica para ser traduzido em palavras.

Consideramos relevante esclarecer que, nos alinhando a Besset et al. (2010) e Leite e Pereira (2003), julgamos que compreender a fibromialgia sob o prisma das formulações psicanalíticas acerca da histeria não constitui um procedimento generalizável, ainda que seja possível em certos casos. A propósito, Fortes, Winograd e Medeiros (2015) e Zanotti et al. (2013) - em publicações recentes que também não foram recuperadas a partir da estratégia de localização empregada para os fins do presente estudo por não abordarem especificamente a fibromialgia - igualmente apontam que a dor crônica não necessariamente equivale a um sintoma histérico. A fim de acrescentar aos argumentos apresentados pelas referidas autoras para sustentar este ponto de vista, sublinhamos que, para consolidar teoricamente a existência de denominadores comuns entre a fibromialgia e a histeria, seria relevante esclarecer como operaria a complacência somática ${ }^{2}$ de modo a viabilizar a emergência de dores difusas. E isso não foi feito por Bittencourt e Pollo (2014) ou por Slompo e Bernardino (2006).

Para encerrar a apreciação das publicações que constituíram o corpus do presente estudo, é preciso ressaltar que Aragon (2010) defendeu que a fibromialgia, concebida como uma expressão do sofrimento contemporâneo, estaria relacionada a dificuldades no processo

\footnotetext{
${ }^{2}$ Em obras como Fragmentos da análise de um caso de histeria, dentre outras, Freud (1996a) deixou claro que, em conformidade com suas premissas, a referida condição psicopatológica decorreria de um conflito psíquico inconsciente, em particular de natureza sexual, que, tendo sido recalcado, seria convertido para o plano corporal. Porém, o autor frisou que este processo somente se efetivaria à custa de um fenômeno que chamou de "complacência somática", por meio do qual emergiriam pontos de fragilidade anatômicos dotados de valor simbólico. Com isso, os sintomas corporais da histeria - como as parestesias, as paralisias e até mesmo a dor seriam circunscritos a certas partes do corpo, as quais variariam de um caso para outro.
}

\section{POLÊM!CA $\mid$ LABORE}


de integração entre o soma e os afetos, sendo que este decorreria do holding materno. $\mathrm{O}$ autor justificou tal formulação destacando que muitas pacientes vivenciariam uma espécie de desapropriação dos ritmos próprios, o que geraria uma despersonalização por meio da qual seriam mobilizadas agonias primitivas e o corpo passaria a ser visto como algo desvinculado das experiências subjetivas. Em um sentido mais amplo, esses resultados vão ao encontro do que propuseram Britto et al. (2014) e Filippon et al. (2013) ao salientar que experiências das primeiras etapas da infância poderiam funcionar como predisponentes da fibromialgia na idade adulta, bem como dialogam com as formulações de Besset (2014), por meio das quais a fibromialgia foi associada ao capitalismo, na medida em que tal sistema econômico produziria formas clínicas distintas ao fragilizar os laços sociais e fomentar sintomas destituídos de sentido.

Cabe ainda esclarecer que tanto Aragon (2010) quanto Slompo e Bernardino (2006) conectaram a fibromialgia às reverberações da contemporaneidade no tocante à emergência de novas modalidades de sofrimento psíquico. Neste ponto, podemos depreender que as publicações em questão encontram respaldo, ainda que remotamente, em Freud, posto que o mesmo observou que os sintomas apresentados por suas pacientes histéricas se encontravam diretamente associados aos ditames culturais da época. Ademais, vão ao encontro das proposições de autores contemporâneos que se alinham às teses freudianas, dentre os quais Birman (2012), o qual salienta que o registro do corpo se sobressai, em detrimento do pensamento e da linguagem, como um dos eixos organizadores do "mal-estar da civilização". A propósito, é relevante mencionar que Freud (1996c) formulou tal expressão para aludir ao sofrimento humano causado pelo inexorável antagonismo existente entre a satisfação dos instintos - condição que julgava essencial para a felicidade - e a civilização, sendo esta entendida basicamente como o conjunto de regulamentos e realizações que nos diferenciam enquanto espécie.

Em suma: no atual estágio do conhecimento científico estabelecido por publicações latino-americanas que abordam a fibromialgia sob a ótica psicanalítica não está claro se a síndrome poderia ser reduzida a uma variante da histeria revestida de uma nova roupagem em consonância com os processos de subjetivação contemporâneos, ou se possuiria um caráter transnosográfico e, assim, poderia se inscrever em diferentes estruturas psíquicas a depender de sua função subjetiva. Porém, foi recorrente a associação entre a fibromialgia e vivências

\section{POLÊM!CA $\mid$ LABORE}


traumáticas precoces, sobretudo relacionadas à sexualidade. Inclusive tal associação é reforçada tanto em publicações selecionadas para os fins do presente estudo que não contemplam diretamente este tópico - como, por exemplo, aquela de autoria de Bittencourt e Pollo (2014) - quanto em publicações que não abordam a fibromialgia sob a ótica da Psicanálise, conforme revela uma revisão da literatura empreendida por Häuser et al. (2011). Todavia, pontuamos certas ressalvas no tocante a esta questão. Ademais, ressaltamos que, conforme as publicações que constituíram o corpus do presente estudo nas quais foram relatadas experiências, as vivências traumáticas precoces que estariam atreladas ao surgimento da fibromialgia poderiam ser elaboradas a partir da situação terapêutica, sendo que a dor física típica da síndrome não representaria um sintoma a ser eliminado, mas, sim, traduzido em palavras.

\section{Considerações finais}

Diante do exposto, é possível propor que o presente estudo responde à questão norteadora que o orientou, ensejando, assim, um mapeamento do conhecimento já produzido sobre a fibromialgia desde a perspectiva da Psicanálise e difundido em diferentes veículos latino-americanos disponíveis nas bases de dados consultadas. Logo, entendemos que os resultados reportados podem fornecer elementos potencialmente proveitosos para a prática de profissionais de saúde que trabalham junto a pacientes acometidas pela síndrome. Da mesma forma, podem contribuir para o aprofundamento teórico sobre o assunto, na medida em que apontam caminhos para a realização de novos estudos, os quais, inclusive, se revelam necessários face à escassez de publicações disponíveis atualmente. Não obstante, outras revisões sobre a temática em pauta podem ser desenvolvidas a partir do exame de publicações de origem distinta, sendo que, com isso, eventualmente resultados complementares em relação àqueles reportados no presente estudo podem ser obtidos.

\section{Referências}

ANDRÉ, J. Vocabulário básico da Psicanálise. São Paulo: Martins Fontes, 2015.

ARAGON, L. E. P. Fibromialgia: perspectivas de um campo problemático. Interface, Botucatu, v. 14, n. 32, p. 155-169, mar. 2010. Disponível em: <http://www.scielo.br/scielo.php?script=sci_arttext\&pid=S141432832010000100013\&lng=en\&nrm=iso>. Acesso em: 25 out. 2016.

\section{POLÊM!CA $\mid$ LABORE}


BELLATO, E. et al. Fibromyalgia syndrome: etiology, pathogenesis, diagnosis, and treatment. Pain Research and Treatment, London, v. 2012, article ID 426130, p. 1-17, set. 2012. Disponível em: <https://www.hindawi.com/journals/prt/2012/426130/abs/>. Acesso em: 31 out. 2016.

BIRMAN, J. O sujeito na contemporaneidade: espaço, dor e desalento na atualidade. Rio de Janeiro: Civilização Brasileira, 2012.

BESSET, V. L. Um sujeito no mercado das pílulas. Revista Latinoamericana de Psicopatologia Fundamental, São Paulo, v. 17, n. 3, supl. 1, p. 616-625, set. 2014. Disponível em: $<$ http://www.scielo.br/scielo.php?script=sci_arttext\&pid=S1415-47142014000600616\&lng=en\&nrm=iso〉. Acesso em: 31 out. 2016.

BESSET, V. L. et al. Um nome para a dor: fibromialgia. Revista Mal-Estar e Subjetividade, Fortaleza, v. 10, n. 4, p. 1245-1270, dez. 2010. Disponível em:

<http://pepsic.bvsalud.org/scielo.php?script=sci_arttext\&pid=S1518-61482010000400009\&lng=pt\&nrm=iso>. Acesso em: 31 out. 2016.

BITTENCOURT, J.; POLLO, V. Fibromialgia: histeria da atualidade? Marraio, Rio de Janeiro, n. 27, p. 108114, jul. 2014.

BRITTO, M. G. A.; SANTOS, N. O.; LUCIA, M. C. S. Evento traumático, fibromialgia e complicações na saúde: um estudo de caso. Psicologia Hospitalar, São Paulo, v. 12, n. 1, p. 26-48, jan. 2014. Disponível em: <http://pepsic.bvsalud.org/scielo.php?script=sci_arttext\&pid=S1677-74092014000100003\&lng=pt\&nrm=iso〉. Acesso em: 31 out. 2016.

CAMPEZATTO, P. M.; NUNES, M. L. T.; SILVA, M. R. Pesquisa em psicoterapia e psicanálise. Aletheia, Canoas, n. 43-44, p. 213-226, ago. 2014. Disponível em:

<http://pepsic.bvsalud.org/scielo.php?script=sci_arttext\&pid=S1413-03942014000100016\&lng=pt\&nrm=iso>. Acesso em: 25 out. 2016.

CARDOSO, M. R.; PARABONI, P. Dor física crônica: uma estratégia de sobrevivência psíquica? Revista MalEstar e Subjetividade, Fortaleza, v. 10, n. 4, p. 1203-1220, dez. 2010. Disponível em:

<http://pepsic.bvsalud.org/scielo.php?script=sci_arttext\&pid=S1518-61482010000400007〉. Acesso em: 25 out. 2016.

CLAUW, D. J. Fibromyalgia: a clinical review. Journal of the American Medical Association, Boston, v. 311, n. 15, p. 1547-1555, abr. 2014. Disponível em: <http://emerge.org.au/wp-content/uploads/2014/12/Clauw-D.-J.Fibromyalgia-a-clinical-review.-JAMA-J.-Am.-Med.-Assoc.-2014-31115-1547-1555.pdf >. Acesso em: 31 out. 2016.

DREHER, A. U. Pluralismo na teoria e na pesquisa: e agora? Revista Brasileira de Psicanálise, São Paulo, v. 42, n. 2, p. 131-153, jun. 2008. Disponível em:

<http://pepsic.bvsalud.org/scielo.php?script=sci_arttext\&pid=S0486-641X2008000200012\&lng=pt\&nrm=iso>. Acesso em: 31 out. 2016.

EIZIRIK, C. L. Psicanálise como uma obra em construção. Revista de Psicanálise da Sociedade Psicanalítica de Porto Alegre, Porto Alegre, v. 12, n. 2, jul. 2005. Disponível em:

<http://site.sppa.org.br/info_conteudo_revista/401>. Acesso em: 31 out. 2016.

ELIA, L. Psicanálise: clínica e pesquisa. In: ALBERTI, A.; ELIA, L. (Orgs.). Clínica e pesquisa em psicanálise. Rio de Janeiro: Rios Ambiciosos, 2000. p 19-35.

FILIPPON, A. P. M. Fibromialgia: um fenômeno de difícil compreensão. In: VI SIMPÓSIO INTERNO INTEGRADO DA ASSOCIAÇÃO DE CANDIDATOS DO INSTITUTO DE PSICANÁLISE DA SOCIEDADE PSICANALÍTICA DE PORTO ALEGRE, 2012, Porto Alegre. Anais... Porto Alegre, p. 31-41.

\section{POLÊM!CA $\mid$ LABORE}

Polêmica - Revista Eletrônica da Uerj - Rua São Francisco Xavier, 524, $1^{\circ}$ andar

bloco D, sl.1001 • Tels.: +55 21 2334-4088/4087 • http://www.e-publicacoes.uerj.br/index.php/polemica/index http://www.labore.uerj.br • laboreuerj@yahoo.com.br 
FILIPPON, A. P. M. et al. Association between childhood trauma and loss of functionality in adult women with fibromyalgia. Trends in Psychiatry and Psychotherapy, Porto Alegre, v. 35, n. 1, p. 46-54, jan. 2013.

Disponível em: <http://www.scielo.br/scielo.php?script=sci_arttext\&pid=S2237-

60892013000100006\&lng=en\&nrm=iso>. Acesso em: 31 out. 2016.

FORTES, I.; WINOGRAD, M.; MEDEIROS, C. A dor crônica entre o silêncio e o grito. Tempo Psicanalítico, Rio de Janeiro, v. 47, n. 2, p. 9-28, dez. 2015. Disponível em:

<http://revista.spid.com.br/index.php/tempopsicanalitico/article/view/60/pdf_45〉. Acesso em: 25 out. 2016.

FREUD, S. (1905). Fragmentos da análise de um caso de histeria. In: SALOMÃO, J. (Org.). Edição standard brasileira das obras psicológicas completas de Sigmund Freud. Rio de Janeiro: Imago, 1996a. v. 12, p. 1-119.

(1926). Psicanálise. In: SALOMÃO, J. (Org.). Edição standard brasileira das obras psicológicas completas de Sigmund Freud. Rio de Janeiro: Imago, 1996b. v. 20, p. 253-259.

(1930). O mal-estar na civilização. In: SALOMÃO, J. (Org.). Edição standard brasileira das obras psicológicas completas de Sigmund Freud. Rio de Janeiro: Imago, 1996c. v. 21, p. 81-117.

HÄUSER, W. et al. Emotional, physical, and sexual abuse in fibromyalgia syndrome: a systematic review with meta-analysis. Arthritis Care \& Research, Hoboken, v. 63, n. 6, p. 808-820, jun. 2011. Disponível em: <http://onlinelibrary.wiley.com/doi/10.1002/acr.20328/full>. Acesso em: 31 out. 2016.

HEYMANN, R. E. et al. Consenso brasileiro do tratamento da fibromialgia. Revista Brasileira de Reumatologia, São Paulo, v. 50, n. 1, p. 56-66, jan. 2010. Disponível em: $<$ http://www.scielo.br/scielo.php?script=sci_arttext\&pid=S0482-50042010000100006\&lng=en\&nrm=iso〉. Acesso em: 31 out. 2016.

LEITE, A. C. C.; PEREIRA, M. E. C. Sofrimento e dor no feminino: fibromialgia - uma síndrome dolorosa. Psychê: Revista de Psicanálise, São Paulo, v. 7, n. 12, p. 97-106, dez. 2003. Disponível em: <http://www.redalyc.org/articulo.oa?id=30701207>. Acesso em: 31 out. 2016.

LIMA, C. P.; CARVALHO, C. V. Fibromialgia: uma abordagem psicológica. Aletheia, Canoas, n. 28, p. 146158, dez. 2008. Disponível em <http://pepsic.bvsalud.org/scielo.php?script=sci_arttext\&pid=S141303942008000200012\&lng=pt\&nrm=iso >. Acesso em : 31 out. 2016.

MENKÈS, C. J.; GODEAU, P. La fibromyalgie. Bulletin de L'Académie Nationale de Médicine, Paris, v. 191, n. 1, p. 143-148, jan. 2007. Disponível em: <http://www.academie-medecine.fr/publication100035630/>. Acesso em: 31 out. 2016.

MONDRZAK, V. et al. Trauma, causalidade e tempo: algumas reflexões. In: $44^{\circ}$ CONGRESSO DA ASSOCIAÇÃO INTERNACIONAL DE PSICANÁLISE. 2005, Rio de Janeiro. Anais... Rio de Janeiro, p. 1-16. Disponível em:〈febrapsi.org.br/publicacoes/artigos/viviane_ipa.doc〉. Acesso em: 25 out. 2016.

SANTOS, N. A.; RUDGE, A. M. Dor na psicanálise - física ou psíquica? Revista Latinoamericana de Psicopatologia Fundamental, São Paulo, v. 17, n. 3, p. 450-468, set. 2014. Disponível em: $<$ http://www.scielo.br/scielo.php?script=sci_arttext\&pid=S1415-47142014000300450\&lng=en\&nrm=iso〉. Acesso em: 31 out. 2016.

SEMER, N. L. Dor e sofrimento psíquico: uma reflexão sobre as relações e repercussões corpo e mente. Revista Brasileira de Psicanálise, São Paulo, v. 46, n. 3, p. 188-199, jul. 2012.

SILVA, T. A. D.; RUMIM, C. R. A fibromialgia e a manifestação de sofrimento psíquico. Revista Mal-Estar e Subjetividade, Fortaleza, v. 12, n. 3-4, p. 767-792, dez. 2012. Disponível em: <http://pepsic.bvsalud.org/scielo.php?script=sci_arttext\&pid=S1518-61482012000200012\&lng=pt\&nrm=iso>. Acesso em: 31 out. 2016.

\section{POLÊM!CA $\mid$ LABORE}

Polêmica - Revista Eletrônica da Uerj - Rua São Francisco Xavier, 524, $1^{\circ}$ andar

bloco D, sl.1001 • Tels.: +55 21 2334-4088/4087 • http://www.e-publicacoes.uerj.br/index.php/polemica/index http://www.labore.uerj.br • laboreuerj@yahoo.com.br 
SLOMPO, T. K. M. S.; BERNARDINO, L. M. F. Estudo comparativo entre o quadro clínico contemporâneo "fibromialgia" e o quadro clínico "histeria" descrito por Freud no século XIX. Revista Latinoamericana de Psicopatologia Fundamental, São Paulo, v. 9, n. 2, p. 263-278, jun 2006. Disponível em:

<http://www.scielo.br/scielo.php?script=sci_arttext\&pid=S1415-47142006000200263\&lng=en\&nrm=iso>. Acesso em: 31 out. 2016.

SOARES, C. B. et al. Revisão integrativa: conceitos e métodos utilizados na enfermagem. Revista da Escola de Enfermagem da USP, São Paulo, v. 48, n. 2, p. 335-345, abr. 2014. Disponível em:

<http://www.scielo.br/scielo.php?script=sci_arttext\&pid=S0080-62342014000200335\&lng=en\&nrm=iso>. Acesso em: 31 out. 2016.

SOUZA, M. T., SILVA, M. D. \& CARVALHO, R. Revisão integrativa: o que é e como fazer. Einstein, São Paulo, v. 8, n. 1, p. 102-106, jan. 2010. Disponível em: <http://www.scielo.br/pdf/eins/v8n1/pt_1679-4508-eins8-1-0102.pdf>. Acesso em: 31 out. 2016.

TASK FORCE ON TAXONOMY OF THE INTERNATIONAL ASSOCIATION FOR THE STUDY OF PAIN. Classification of chronic pain: descriptions of chronic pain syndromes and definitions of pain terms. Seattle: IASP Press, 1994.

ZANOTTI, S. V. et al. Aux limites de l'hystérie, la douleur chronique. Revista Latinoamericana de Psicopatologia Fundamental, São Paulo, v. 16, n. 3, p. 425-437, set. 2013. Disponível em: $<$ http://www.scielo.br/scielo.php?script=sci_arttext\&pid=S1415-47142013000300006\&lng=en\&nrm=iso〉. Acesso em: 25 out. 2016.

Recebido em: 07/11/2016.

Aceito em: 30/12/2016.

\section{POLÊM!CA $\mid$ LABORE}

